\title{
DE CAMPOS Y ÁRBOLES PARA HABLAR DE MUERTOS EL VIDEOARTE CONTRA LA INDIFERENCIA DE LAS REPRESENTACIONES MEDIÁTICAS
}

Artículo de reflexión

\section{Celia Riboulet}

Universidad Autónoma del Estado de México / ribouletcelia@gmail.com

Artista y teórica francesa, inicia su trayectoria artística en 2001 en el Departamento de Artes Visuales de la Universidad de Toulouse le Mirail, Toulouse. En 2010 dirige un curso teórico sobre arte digital en el Centro Nacional de las Artes (México), que se hilvana en 2011 con un curso práctico y en 2013 con una muestra de Videoarte Latinoamericano. En agosto de 2011 es profesora de tiempo completo en la Universidad Autónoma del Estado de México en la nueva licenciatura en Arte Digital. En agosto de 2012 gana una beca de apoyo a la investigación en Artes y Medios del Centro Multimedia del CENART (México). Ha publicado varios artículos sobre el videoarte en revistas indexadas del continente (Brasil, México, EE.UU.). 
Riboulet, C. (2015) De campos y árboles para hablar de muertos: El videoarte contra la indiferencia de las representaciones mediáticas Calle14, 11(16) pp. 112 - 123

\title{
DE CAMPOS Y ÁRBOLES PARA HABLAR DE MUERTOS EL VIDEOARTE CONTRA LA INDIFERENCIA DE LAS REPRESENTACIONES MEDIÁTICAS
}

\section{RESUMEN}

¿Cuál sería la función de los cineastas y videastas en relación con la imagen televisiva y de otros medios de comunicación? La cuestión política del videasta comprometido podría ser la siguiente: ¿Cómo despertar en cada espectador las dudas y las crisis que el espectáculo (mediático) tiene como meta rechazar y alejar? El artículo describe características básicas del uso de la violencia en la televisión y su respectivo manejo en el arte del video. A partir de las obras de dos videastas- cineastas: Chantal Akerman (Bélgica) y Eliane Chiron (Francia), se analizan cuestiones de poder, imagen e intimidad, relacionadas con el tema y con la representación de la violencia.

\section{PALABRAS CLAVES}

Imagen, violencia, paisaje, tiempo, videoarte.

\section{CHAGRA SACHAKUNAPI WAÑUSKAKUNAWAMANDA RIMANGAPA KAWARIKUIAWA MANA SUGRIGCHA MUNAGATA}

\author{
SUGLLAPI \\ ¿ima ruraitaka uikankuna cineastakuna videastakuna chi kawachidirukunawa sugkunapi \\ televisionpi?videastapi compromiso politikapi kasachar karrinsha. \\ ¿lmasa kawachingapa kawadurta kai kawachikunawa kawangami kawangapamanapa? \\ Kaipi willakumi imasapi llakuchingapa televisionpi imasa video manejangapa munaskasina is- \\ kai videaskakuna: Chantal Akerman (Belgikamanda) Eliane Chiron (Franciamanda), kawanku- \\ na imasa chi jiru kawachikuna jiru.
}

IMA SUTI RIMAI SIMI:

kawari llakichinakui sumakawari pucha, tiempo, video kawari.

\section{ON FIELDS AND TREES TO SPEAK OF THE DEAD: VIDEO ART AGAINST THE INDIFFERENCE OF MEDIA REPRESENTATIONS}

\begin{abstract}
What would the role of film and video makers be regarding the TV image and the image from other media? The political question of the committed video maker could be as follows: how to raise in every viewer the doubts and crises that the (media) spectacle aims to reject? The article describes the basic characteristics of the use of violence on television and how these characteristics are managed in video art. Issues of power, image and intimacy are discussed in connection to the above and to the depiction of violence, guided by the works of two video artists/filmmakers: Chantal Akerman (Belgium) and Eliane Chiron (France).
\end{abstract}

\section{KEYWORDS}

Image, violence, landscape, time, video art. 


\section{DES CHAMPS ET DES ARBRES POUR PARLER DES MORTS : LA VIDEOARTE CONTRE L’INDIFFÉRENCE DES REPRÉSENTATIONS DE MÉDIAS}

\section{RÉSUMÉ}

Quelle pourrait être la fonction des cinéastes et vidéastes par rapport à l'image télévisuelle et autres moyens de communication ? La question politique du vidéaste engagé pourrait être la suivante : comment réveiller dans chaque spectateur les doutes et les crises que le spectacle (médiatique) a pour but de rejeter et d'éloigner ? L'article décrit les caractéristiques de base de l'usage de la violence à la télévision et son maniement dans l'art de la vidéo. À partir des oeuvres de deux vidéastes-cinéastes : Chantal Akerman (Belgique) et Eliane Chiron (France), nous analysons les questions du pouvoir, de l'image et de l'intimité, mises en relation avec le sujet et avec la représentation de la violence.

\section{MOTS CLÉS}

Image, violence, paysage, temps, art vidéo.

\section{CAMPOS E ÁRVORES PARA FALAR DOS MORTOS: VÍDEO-ARTE CONTRA A INDIFERENC̣A DAS REPRESENTAC̣ÕES DAS MIIDIAS}

\section{RESUMO}

Qual seria o papel de cineastas e vídeo sobre a imagem de TV e outras mídias? A questão política de cinegrafista comprometido poderia ser o seguinte: como despertar em cada espectador dúvidas e crises que o show (mídia ) pretende rejeitar e fora? 0 artigo descreve características básicas do uso da violência na televisão e respectiva gestão em video-arte. A partir das obras de dois cineastas videastas: Chantal Akerman (Bélgica) e Eliane Chiron ( França), são discutidas questões de poder, imagem e intimidade de, relacionado com o tema e a representação da violência.

\section{PALAVRAS CHAVES}

Imagem, violência, paisagem, tempo, vídeo-arte.

Recibido 20/08/2014

Aceptado 04/09/2014

DOI: http://dx.doi.org/10.14483/udistrital.jour.c14.2015.2.a10 
Esta investigación se inicia a partir de un cuestionamiento personal: ¿Por qué me estoy acostumbrando a ver imágenes en la televisión que no me gustaría ver? De hecho, ¿quién desearía un mundo en el cual todo se volviera visible? ¿Quién tiene esta insaciable pulsión esópica? Pues nuestro dios, antes que todos. ¿Quién ve todo? ¿Quién quiere ver todo? El dios de los cristianos, claro. Maria Tasinato, en La curiosité (1999), cita a Minucius Félix: " $¡$ Qué tantas extrañezas y quimeras inventaron los cristianos! Afirman que su dios, que no pueden mostrar ni ver, busca conocer meticulosamente el comportamiento, las acciones, las palabras, hasta los pensamientos, de cada uno, paseando por aquí y por allá, estando presente en cada lugar".

En cuanto a nosotros, que no somos dios, ¿qué queremos ver? ¿Qué podemos desear o soportar ver? Poner en duda los deseos del espectador frente a las producciones de imágenes es una acción extraña, la cual nos lleva a una idea más amplia que intenta explicar cómo funciona la relación espectador-imágenes: ¿Quién crea a quién? ¿El espectador crea a la televisión o la televisión crea al espectador? Seguramente la respuesta no se inclina, en su totalidad, por ninguna de las dos opciones, sino que el resultado es una interacción constante en la cual el espectador y las imágenes se alimentan mutuamente.

Me propuse, para esta investigación, estudiar el tratamiento de la violencia en dos medios distintos: La televisión y el videoarte, a partir, particularmente, del tratamiento del "suceso". Para plantear este trabajo, me basé de manera específica en la muerte de un hombre negro llamado James Byrd. El señor Byrd fue linchado por tres hombres blancos en Jasper, Texas; lo amarraron a una camioneta y lo arrastraron sobre la carretera hasta que su cuerpo quedó desmembrado.

En primer lugar, muestro cómo fue tratado el suceso por los medios (televisión y periódico); cito el artículo que publicó el New York Times después de la muerte de James Byrd (Cropper, 1998):

"Black Man Fatally Dragged In a

Possible Racial Killing"

By CAROL MARIE CROPPER

Published: June 10, 1998

A black man was dragged to his death on Sunday from the back of a pickup truck in a rural section of Texas known for racist and Klan activity, and today three white men were charged with the murder.

The broken body of James Byrd Jr., 49, was discovered on Sunday morning by residents of an area just outside the East Texas town of Jasper, population 8,000. As he walked home from his parents' house on Saturday night, Mr. Byrd was apparently picked up by the men sometime after midnight and taken to woods, where he was beaten, then chained to the truck and dragged for two miles.

Guy James Gray, the Jasper County District Attorney, called the killing "probably the most brutal l've ever seen" in 20 years as a prosecutor. Mr. Byrd's torso was found at the edge of a paved road, his head and an arm in a ditch about a mile away, according to an affidavit.

The police charged Shawn A. Berry, 23, Lawrence R. Brewer, 31, and John W. King, 23, with murder. The District Attorney said Mr. Brewer and Mr. King had racist tattoos and were Ku Klux Klan supporters, leading investigators to believe the killing was racially motivated. ${ }^{1}$

¿Qué nos dice esta noticia?:

1.Nos informa de la muerte de un hombre. 2.Nos da el motivo: Un crimen racial. 3.Nos da alguna información sobre la actividad de James Byrd antes de su muerte y sobre su pueblo, Jasper.

4.Nos indica dónde fueron encontrados las partes del cuerpo.

5.Nos dice quiénes son los culpables.

1.

\author{
"Hombre negro arrastrado mortalmente, \\ posible crimen racial" \\ por Carol Marie Cropper \\ Publicado el 10 de junio de 1998
}

Un hombre negro fue arrastrado hasta su muerte este sábado, amarrado de una camioneta en un territorio rural de Texas, conocido por su racismo y la presencia del clan. Hoy, tres hombres blancos fueron acusados del asesinato. El cuerpo desmembrado de James Byrd Junior, de 49 años, fue descubierto el sábado en la mañana por unos habitantes de los afueras de la ciudad de Jasper (8.000 habitantes). Mientras caminaba de regreso de la casa de sus padres a su casa el sábado en la noche, el señor Byrd fue, al parecer, recogido por los hombres un poco después de medianoche y llevado al bosque, en donde lo golpearon y después fue encadenado a la camioneta y arrastrado 2 millas [3.2 km). Guy James Gray, el fiscal del distrito de Jasper, calificó el asesinato "probablemente como el más brutal que haya visto" en 20 años de servicio. Según la declaración, el torso del señor Byrd fue encontrado al borde de una carretera pavimentada, su cabeza y un brazo en una zanja una milla más lejos.

La policía arrestó a Shawn A. Berry, de 23 años, Lawrence R. Brewer, de 31 años, y a John W. King, de 23 años, quienes fueron acusados del asesinato. El fiscal del distrito dijo que los acusados Brewer y King tenían tatuajes racistas en el cuerpo y eran integrantes del Ku Klux Klan. Estos elementos hacen pensar a los investigadores que la muerte fue motivada por cuestiones raciales. 

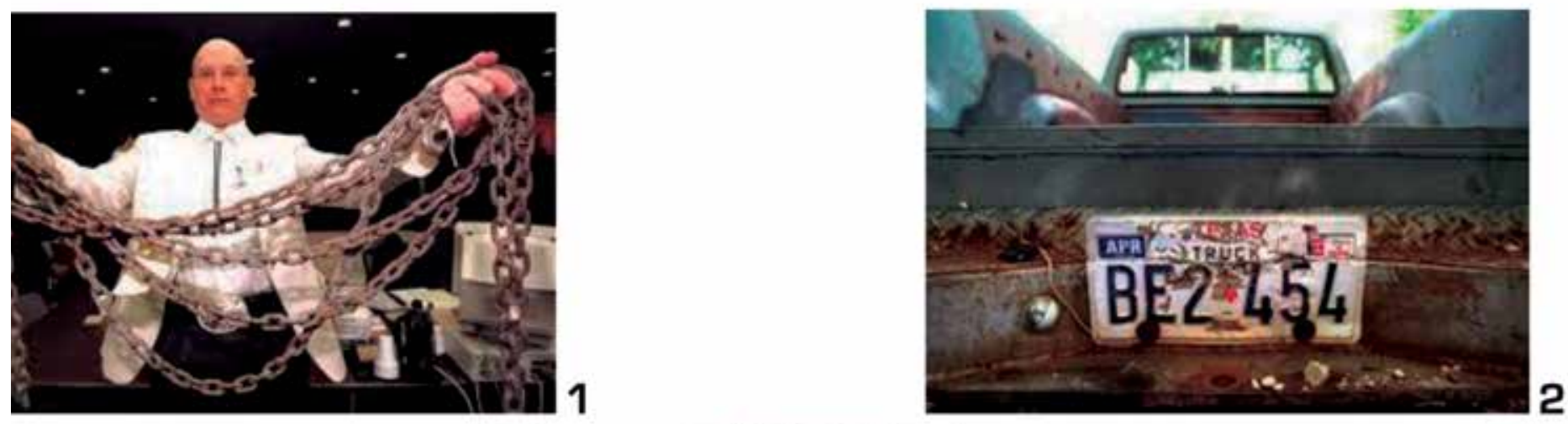

\section{1}
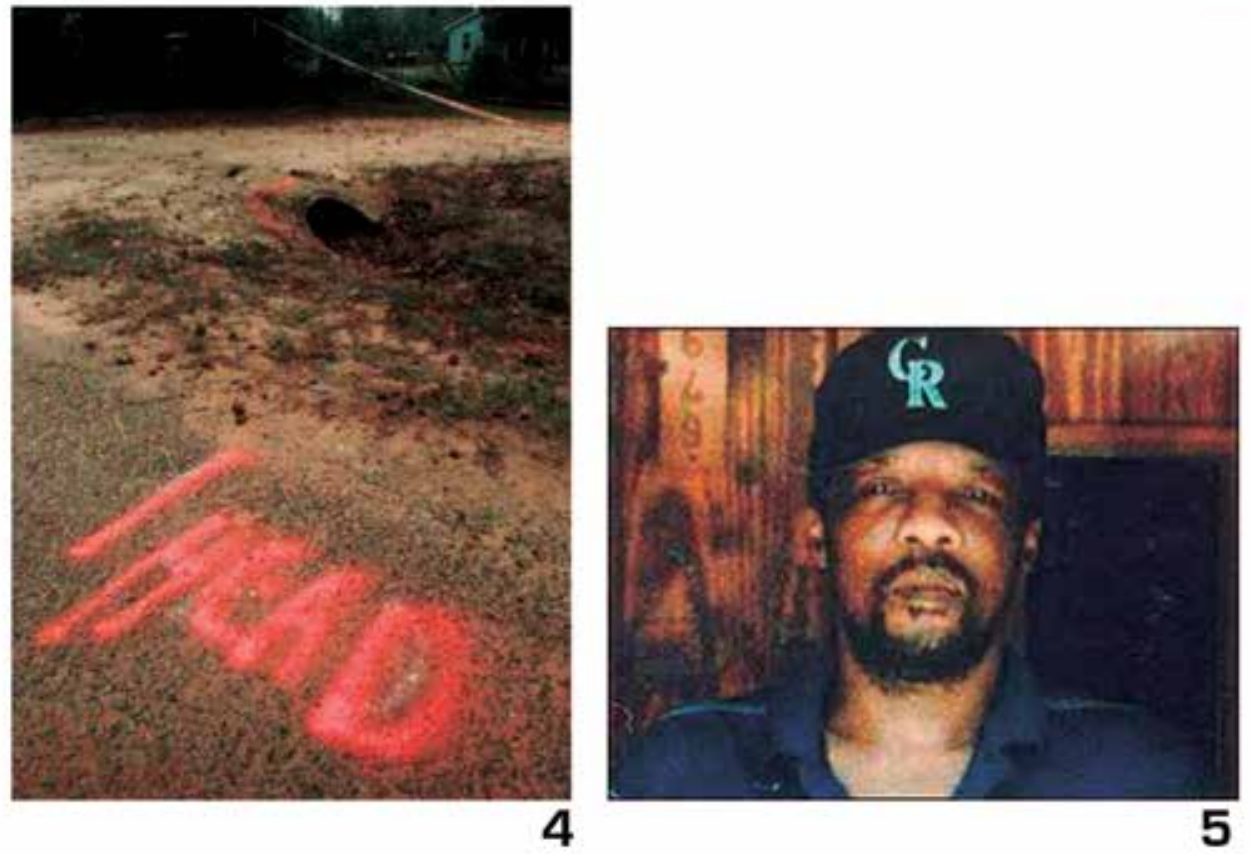

$\Delta$ Figuras 1, 2, 3, 4, 5: Imágenes relacionadas con la muerte de James Byrd, obtenidas en Google.

A continuación se reproducen algunas imágenes publicadas en los medios acerca de la misma muerte:

Las imágenes nos muestran a James Byrd vivo, los objetos utilizados para amarrarlo y arrastrarlo, la camioneta de los culpables y los lugares donde fueron encontrados sus restos. Me pregunto: ¿Cuál es mi sensación al leer esta noticia? y, más ampliamente, ¿cuál es mi sensación al ver los cuerpos expuestos en los noticiarios? En un primer momento, es asco, así como indignación y, al mismo tiempo, impotencia.

Me interesaría entender cómo se crearon estas imágenes para poder comprender cómo se teje la relación entre el espectador (y ellos, espectadores), yo, y las imágenes de los noticieros. Realizaré unas preguntas básicas para intentar comprender la construcción de estas imágenes:

1. ¿Quién habla? Es difícil distinguir exactamente quién habla. Tenemos, en primer lugar, al camarógrafo, quien decide qué grabar y qué no. Es él quien se acerca, o no, al cuerpo, además de decidir lo que se puede mostrar o no (claro que después interviene la selección de la redacción de los periódicos y noticieros].
2. ¿Desde qué punto de vista se selecciona, encuadra lo real? Desde una historia personal que nos es desconocida. El punto de vista es el del periodista que tiene una historia personal, una vida, conflictos, lagunas, fallos, deseos, etc. No es un punto de vista neutro. Es el punto de vista de alguien que desconocemos pero que se hace presente por medio de la imagen. Lo único que se sabe es: El que graba está trabajando, al fotografiar o grabar los sucesos y otras actualidades, entre tantos muertos.

3. ¿Según qué relaciones de fuerza se graba y en qué posiciones o suposiciones de poder? El que graba tiene todo el poder, sabiendo que si lo que graba es inanimado, no pondrá objeciones ni críticas a sus imágenes. Para hacer lúdico esto, nos podríamos preguntar: ¿james Byrd hubiera estado de acuerdo con la manera en que presentaron la historia de su muerte, exhibiendo los restos de su cuerpo, su fotografía? ¡Seguramente no! Las imágenes se apropian de la muerte con mucha facilidad, sin pudor ni poesía.

4. ¿Cómo se presentan estas imágenes? Se presentan en los noticieros televisivos de una manera intercalada entre muchas otras; es decir, a la muerte 
de James Byrd la precedió quizás una noticia acerca de desastres financieros y le sucedió, tal vez, una información sobre el cambio climático; y en los periódicos, de igual manera, la noticia y las imágenes relacionadas con la muerte de James Byrd colindan con informaciones diversas. Es decir, prácticamente después de haberme conmocionado con la muerte de James Byrd, otra noticia viene a distraerme. La muerte está ya en el pasado, ¿qué puedo hacer yo?

¿Podríamos hacernos estas preguntas si no existiera un destino grabado de las imágenes en nuestras sociedades, un volver-imagen, un destino de las imágenes de los muertos? Es decir, las imágenes de los muertos tendrían ya una función definida y cerrada dentro de los noticieros.

¿Cuál sería ese destino? Para contestar esta pregunta podríamos recurrir a Mitologías de Roland Barthes (1957), obra que trata sobre el asesinato político y el asesinato que forma parte del suceso. El primero es una información parcial que remite a una situación extensiva, la cual existe fuera, antes y alrededor de él: la política. En este caso, la información no se puede entender inmediatamente porque se necesita tener conocimiento de una causa exterior al suceso para comprenderla. En el asesinato que forma parte del suceso toda la información está proporcionada para que sea entendido el suceso. En un asesinato pasional u hombre asesinado por un "loco", el hecho está completo, contiene todo para su comprensión.

En el asesinato político, para entender las razones de la muerte, el espectador debe tener conocimiento del contexto, o de la historia, o de lo que permite explicar la muerte. En el caso del racismo, sería pertinente regresar a los orígenes de los Estados Unidos para entender cómo puede surgir tanta violencia de la raza blanca contra los negros. Pero los medios no buscan instruir al espectador ni investigar los contextos. Los medios sólo asedian al espectador visualmente, exagerando la realidad; nos dan el hecho, lo que fue, sin su posibilidad ni su potencia. Los medios quieren a un espectador indignado pero impotente.

No sabemos casi nada de James Byrd; sabemos quizás más de sus asesinos, de los utensilios que sirvieron para matarlo, de los lugares en los cuales fueron encontrados los restos de su cuerpo, pero pocos elementos permiten acercarnos a lo que fue James Byrd. Los medios se interesan en la apariencia de la muerte: Sanguinaria y ultraviolenta. Lo que muestran es una cierta adicción por las enfermedades mentales, por las derivas de la sociedad, por lo irracional, la locura. Por eso existe una cierta preferencia por conocer las características físicas y mentales de los asesinos, por los detalles de la muerte, la manera en la cual se fragmentó el cuerpo. El hombre, James Byrd, como tal, no le interesa a los medios, ellos no tienen realmente el objetivo de informar, distraen la atención para desplazarla hacia territorios delimitados y resguardados.

De allí la desconfianza y el miedo de los espectadores hacia este medio que es la televisión (Comolli, 2004):

Todo lo que pasa en la televisión le da la impresión, a la gente del pueblo, de no tener allí ningún lugar, o peor aún: Un lugar fijo por anticipado. [...] Y todo lo que rige este tratamiento del habla desprovisto de cualquier respeto, hecho de cortes, de tijeras, de la eliminación de los silencios, de las indecisiones, del pulso de la lengua, no deja a nadie indiferente. Sin reconocerlo, es esto de lo que la gente sufre. El poder de los que ocupan la pantalla sobre los que la miran.

Es decir, la televisión otorga a la gente del pueblo un lugar técnicamente definido, estereotipado. La televisión, tal cual existe, es una máquina para conservar. Los lugares son asignados.

La acción de escuchar (grabar equivale a escuchar) desapareció ya en la actualidad. ¿Quién escucha a alguien? ¿Durante cuánto tiempo? La televisión no escucha, la televisión es un lugar en el cual uno tiene que ser breve, contundente, reiterando fórmulas, no lengua ni palabra. Los muertos de la televisión, de los noticieros, sirven para alimentar el morbo de los espectadores.

¿Cuál sería la función de los cineastas, videastas, en relación con la imagen televisiva? La cuestión política del cineasta comprometido podría ser la siguiente: ¿cómo despertar en cada espectador las dudas y las crisis que el espectáculo (televisión) tiene como meta rechazar y alejar? Es decir, la meta del cineasta no es hablar añadiendo palabras sobre la palabra ambiente, sino hacer entender. Es muy ingenuo pensar que basta con una cosa dicha en el cine para que sea entendida, la misma ingenuidad al pensar que una cosa mostrada será vista. Lo que se dice está ya dicho siempre; el problema del cineasta será hacerlo entender.

Estudiaremos la película Sud de Chantal Akerman, realizada a partir del suceso acontecido a James Byrd en 1999. La película inicia sin explicación alguna; desfilan paisajes comunes de zonas parcialmente rurales. Entre estos paisajes, a veces, la cineasta se detiene a grabar los recuerdos del esclavismo, contados por una señora mayor o la voz de un funcionario judicial, y continúa luego su camino sobre carreteras llenas de casas de madera, campos o árboles... Entre las entrevistas y los paisajes, se inicia una extraña resonancia, las palabras de la señora encuentran asombrosas 

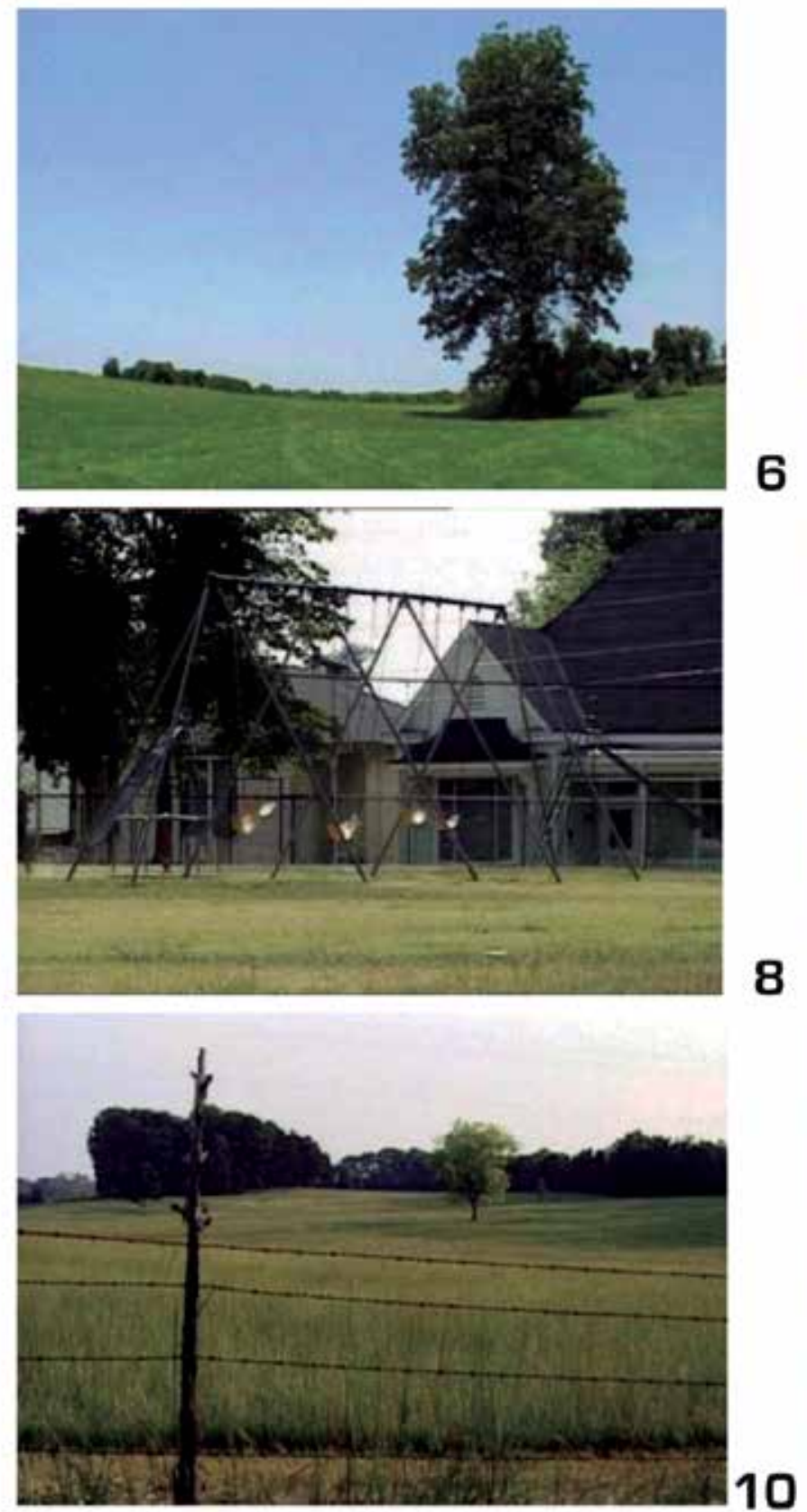

A Figuras 6,7,8,9,10,11: Videoframes de la película Sud, Chantal Akerman, 1998.

relaciones con las imágenes: de repente, en el árbol, se balancea un colgado; en los campos de algodón, se escuchan los latigazos; en los caminos, suena la caza del hombre. Nada se exhibe, pero todo está allí, en esta naturaleza silenciosa. La película termina con la misa de entierro de James Byrd y con un travelling por la carretera sobre la cual fue arrastrado.

Contrariamente a los noticieros, la película de Chantal Akerman no plantea de manera directa la temática del asesinato. No sabemos realmente qué está pasando en cuanto inicia la película. Las imágenes nos dejan hundidos en unos espacios desconocidos, acercándonos lentamente a un hecho terrible, a una historia pasada, cuyos paisajes resultan ser la memoria más directa. Y esta fusión de los paisajes, de las imágenes, se logra a través de un tiempo particular. En una entrevista, "Cinéma Cinéaste" (2012), Chantal Akerman dice: "Voy sin idea e intento ser
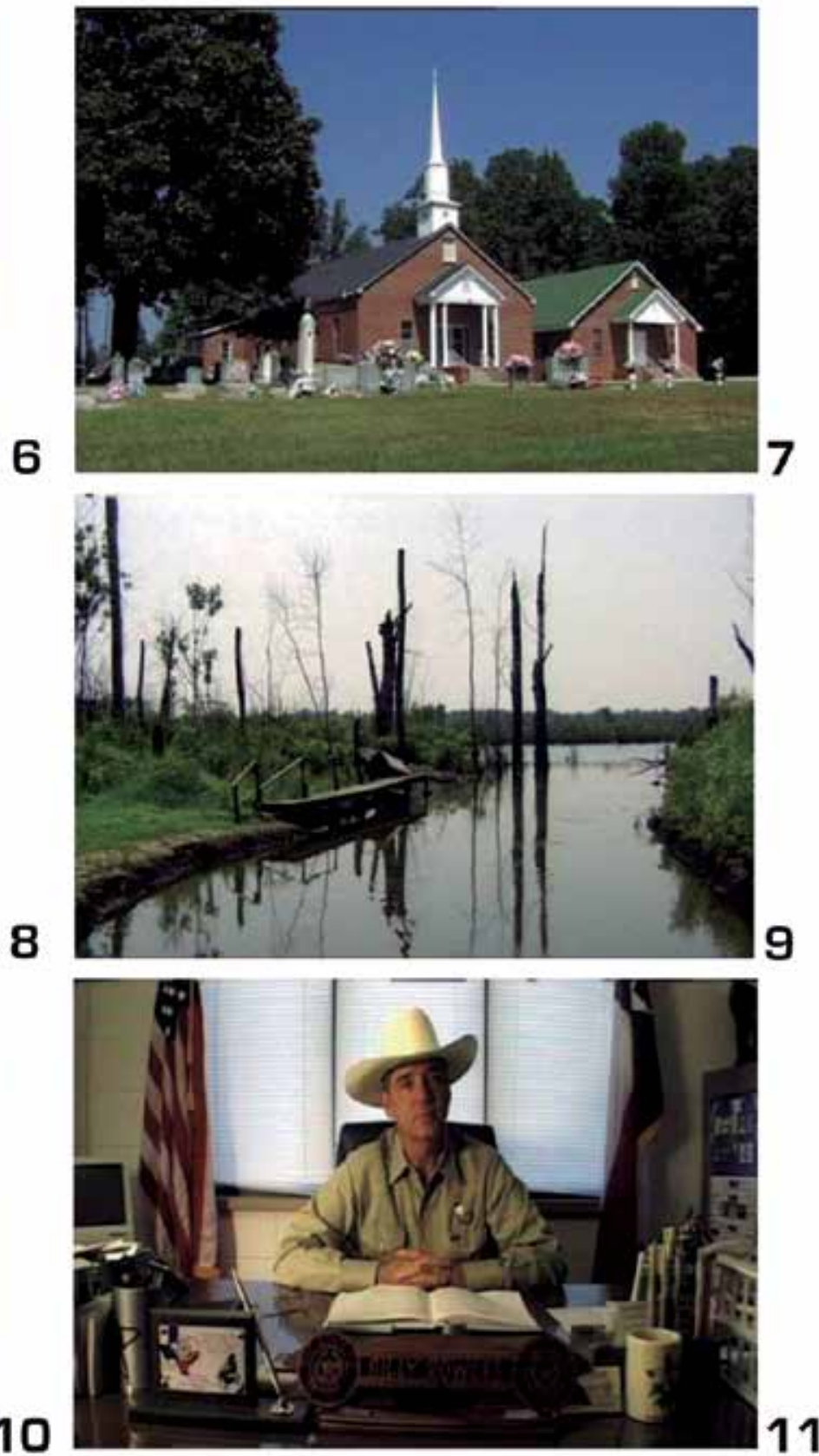

una esponja y absorbo lo que veo." Es parecido lo que experimenta el espectador al mirar Sud: Una esponja que se carga de estos paisajes, palabras, imágenes, hasta mezclarlas, superponerlas, para sugerir que se abren las relaciones, las historias y empiezan a hablar. Después de un tiempo, las palabras de los negros, del funcionario judicial, de los integrantes del Ku Klux Klan, empiezan a trazar una cartografía de los paisajes, de la historia, a través de la memoria y de la huella. Los paisajes se visten en el imaginario de una dimensión exterior. Lo que está en juego en Sud es describir en la imagen el interior de un exterior (paisaje).

En esta película, funcionan unos elementos básicos a modo de dispositivo:

-El tiempo de las imágenes que permite el trabajo de la memoria, la cual recuerda, construye, narra. -Los travellings o planos fijos de paisajes. 


\section{EI tiempo de las imágenes}

En otra entrevista a Chantal Akerman (2003), Laurent Devanne le pregunta lo siguiente:

Entrevistador: Tengo la impresión de que en la duración de la imagen, la imagen se transforma. Como lo decía hace poco, existe esta pared que se vuelve otra pared [...]

C. Akerman: Primero se ve una pared, luego pensamos en otros muros y en lo que hicieron a la gente. Lo mismo pasa en Sud, vemos un árbol, después de un tiempo -y lo dejo suficiente tiempo- pensamos en que gente fue colgada de estos árboles. Y de nuevo vemos el árbol y se escucha el sonido y el sonido evoca otras cosas. Lo mismo en el campo de algodón; lo vemos vacío, escuchamos abejas, el ruido del viento en el algodón y después ya no se puede hacer nada, pensamos en los esclavos y, cuando lo hacemos, pensamos en todos los esclavos de la humanidad. Cada vez se abre más el imaginario. Pasa también de lo concreto a lo abstracto; a veces, los planos se vuelven abstractos y luego regresan a lo concreto. Abre el imaginario de la gran historia, pero, simultáneamente, también el personal, el de cada uno con su pequeña historia."

Efectivamente, el tiempo de la imagen es fundamental. Al dejar suficiente tiempo una imagen, el espectador está invitado a mirarla con más detenimiento, a observarla, a desplazarse en ella. "Entramos en su propio imaginario (del espectador) y tenemos una sensación, y esto no es información, es sentir. La información la vemos todos los días y la gente la olvida al día siguiente. Sí." (Akerman, 2003). Es decir, el tiempo, si no transforma directamente la imagen, transforma la mirada del espectador. Si yo, espectador, miro en una película un paisaje, por ejemplo un campo, y este sirve de contexto para la historia (para describir el entorno en el cual se desarrolla la historia o el personaje), entonces, el campo va a aparecer en la pantalla por un tiempo corto. Pero si el paisaje se vuelve la historia (el paisaje es en sí mismo actor, historia), entonces, el campo va a quedarse en la pantalla el tiempo suficiente para que el espectador pueda entender que el campo no es solamente un elemento del ambiente, sino parte de la historia o la historia misma; por lo tanto, lo puede valorar, observar, estudiar, disfrutar. El tiempo da un sentido a la imagen: la transforma. Transforma el paisaje en algo vivo, activo.

\section{Los paisajes en la pantalla}

Los paisajes tienen un lugar principal en esta película. Chantal Akerman filmó los paisajes con el mismo detenimiento con el cual grabó a los testigos y personas entrevistadas. Si los paisajes no tienen palabras, es porque se expresan de otra forma, y el tiempo que aparecen en la pantalla es justamente para poder observarlos detenidamente como testigos de la historia.

Algo extraño sucede cuando prevalece la figura humana en el cine occidental. Miremos por ejemplo la pintura del pintor chino Dong Yuan intitulada Un pueblo campesino deseando la bienvenida al Dragón (el dragón, aquí, significa, el emperador). A primera vista, solamente observamos un paisaje montañoso, pero mirando con más atención se pueden percibir pequeñitos puntos blancos en comparación con el paisaje, que son los campesinos y el emperador con sus seguidores. Varias pinturas chinas (como la ilustración) exhiben la misma indiferencia frente a la figura humana, como una especie de respeto minucioso hacia el paisaje que la contiene.

Esta inclusión del paisaje en la imagen nos hace pensar que un ser humano no siempre tiene que ser el más cercano a nosotros en la imagen. El reino animal, el vegetal y el mineral pueden igualar o superar la función que el hombre tiene generalmente en la imagen. La atención de la cineasta se extiende a todo lo vivo. Podríamos relacionar esta insistencia en lo vegetal con lo que Raúl Ruiz (teórico que escribió una poética del cine) calificó como "cine chamánico":

Al final, solamente hablo de un cine capaz de inventar una nueva gramática cada vez que pasa de un mundo a otro, capaz de producir una emoción particular frente a cada cosa, animal o planta, solamente modificando el espacio y la duración. Pero esto implica una práctica constante, a la vez de atención y de desprendimiento, la capacidad de pasar de la acción de grabar, y de regresar, al siguiente instante, a la pasividad contemplativa.

En resumen, un cine capaz de dar cuenta en prioridad de las variedades de la experiencia del mundo sensible. Fácil de decir. (Ruiz, 1995)

Esta práctica constante de la cual habla Raúl Ruiz, haciendo referencia a la atención y al desprendimiento, tiene que ver con una escritura previa a la película, que se teje y se genera en la relación o atención del artista con el mundo. Porque la película resulta ser el fruto de esta experiencia del mundo sensible. Esta experiencia es lo que va a dar vida consecuentemente a la imagen, porque, aunque podría parecer evidente o sin importancia, la relación que construye el artista con las personas grabadas o los paisajes es esencial. Parte de la calidad de esta relación es la que va a dar un sentido, un tono a la imagen. En los detalles del acercamiento se establece lo esencial de lo que se pone en juego después en la película. 


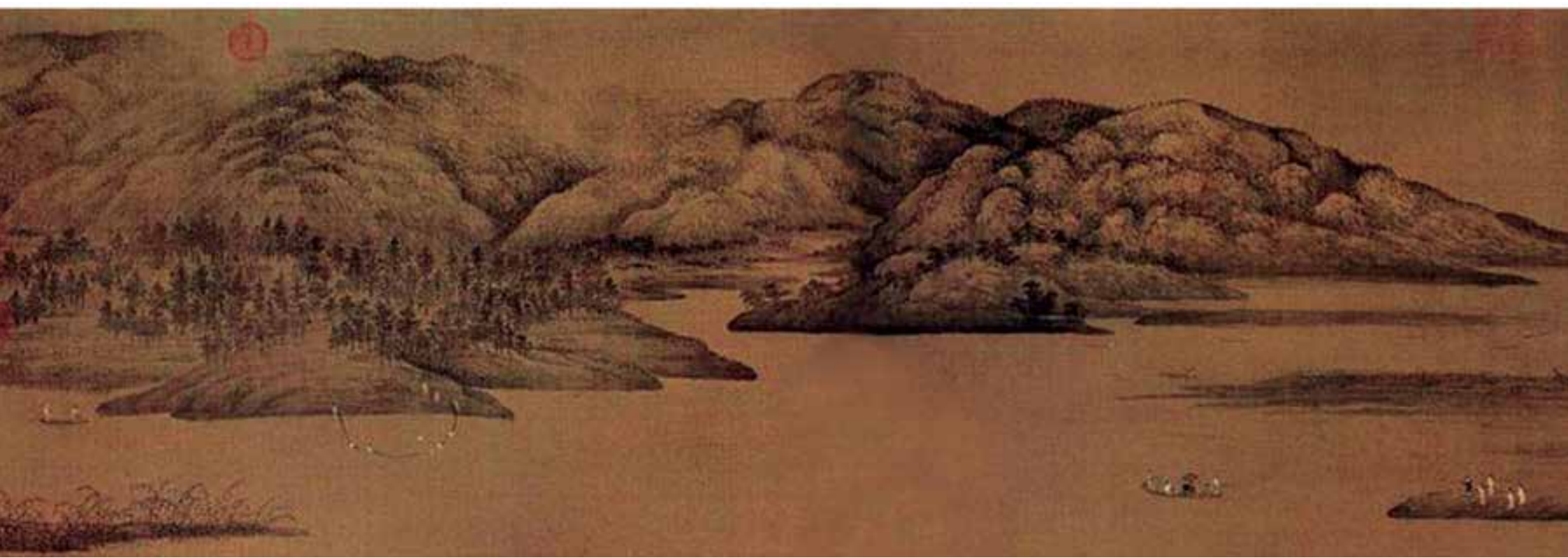

- Figura 12: Tung Yuan (c. 932-962)

Aquí es pertinente traer a Louis Comolli, quien propone diferentes estrategias para que la relación entre las personas grabadas y la persona que graba sea más justa y equilibrada en cuanto al reparto de poder. Esta cuestión del poder, del equilibrio entre las dos partes grabador/grabado, podría ser un elemento de la experiencia de la cual habla Raúl Ruiz.

¿Qué podría significar la experiencia del mundo? El que experimenta podría ser el que da un espacio a la experiencia, es decir, a lo que no es conocido, a lo que no se puede prever. En las relaciones grabador/grabado sería dar más lugar a la persona grabada, dar la posibilidad de que surja algo no escrito, no pensado. Lo que propone Louis Comolli (2004) son estrategias para que el encargado de grabar experimente algo que no puede planear ni escribir del todo, con el objetivo de desestabilizar las posiciones o suposiciones de poder entre espectador/imágenes e, implícitamente, entre camarógrafo/personas grabadas. Enseguida Comolli plantea algunas estrategias, entre las cuales cito las siguientes:

1. Invertir la proposición inicial, es decir, “¿Cómo interactúa la cámara con los que graba?” en “¿Cómo juegan ellos con ella?".

2. Organizar lo menos posible la realidad. En este sentido, el que graba no sabe lo que la persona grabada va a hacer.

3. Reducir la distancia entre la cámara y los que son grabados. Se trata de acercar la cámara al espacio del que está siendo grabado, de manera que participe en su zona de equilibrio, en su territorio.

4. Escuchar a la gente. Hacer la toma de imagen pero vivirla como una toma de lenguaje.

5. No intervenir. Estar solamente en algún lugar tras la cámara.

\section{La brume, I'eau, le feu de Eliane Chiron}

Quisiera analizar, ahora, otra obra videográfica de la artista y profesora Eliane Chiron, intitulada La brume, l'eau, le feu. (La nieblina, el agua, el fuego). Esta obra se compone de tres videos con una duración de un minuto y treinta segundos cada uno.

Los videos estratifican diferentes tipos de imágenes. El manglar es la primera capa. Modificado digitalmente, el video del manglar pierde su realismo para volverse un extraño tejido de formas obscuras, claras, brillantes, líquidas, movedizas... De la profundidad de estas extrañas conexiones emerge, como fantasma, otra capa del video, compuesta de rostros, ojos, bocas...; el rostro de la humanidad sin característica clara. Como fantasmas, los rostros se superponen sobre el manglar, dándonos la impresión de que estos cuerpos se quedaron atrapados en un tiempo indefinido, sin pertenecer totalmente al pasado ni al presente porque su textura transparente les da una existencia frágil, susceptible de escapar o de hundirse.

En estos videos, la utilización del tiempo es diferente a la de Sud. Cuando en Sud, el tiempo deja las imágenes en infusiones que se estratifican por sí solas; en La brume, l'eau, le feu, el tiempo funciona, al contrario, como una válvula que abre, regresa y expone, a modo de un recuerdo, las imágenes que vuelven a la superficie.

\section{De lo íntimo}

Me sorprendí en el coloquio "Les technologies dans la peau. De la singularité à la peau du monde" (Las tecnologías en la piel. De la singularidad a la piel del mundo), en el cual conocí estas piezas videográficas de Eliane Chiron, cuando ella dijo que su obra no tenía ningún compromiso político. Ahí empecé a 
relacionar los procesos y las poéticas. En el descanso del coloquio, me acerqué a ella para aclarar esta cuestión de la dimensión política de su obra, porque me había parecido extraño que en el contexto histórico y político de Brasil -y más específicamente de la Amazonia- esta obra pudiera quedarse alejada de una lectura politizada, sobre todo cuando la artista dice que se detuvo a grabar a un niño mestizo que atrajo su atención, porque se imaginó que este podía ser el producto de una violación, fruto de una conquista pasada, una colonización.

Le pregunté por qué pensaba que sus videos no podían tener cierto compromiso político. Para contestar a mi pregunta, Eliane Chiron me contó la historia que condicionó su obra: La muerte de su hermano cuando aún era muy joven. Con ello sostuvo que no tenía que ver con algún contenido político; más bien, se trataba de una historia personal. Entonces, los rostros que aparecían en los manglares eran para ella el rostro de su hermano. La artista confesó que lo que se volvió el centro de esta obra (la muerte de un ser querido) no era inicialmente el leitmotiv de esta, sino que, en los dos años que duró la edición de los videos, ella se dio cuenta de que era ese sentimiento el que la llevaba a acomodar y relacionar las diferentes imágenes y sonidos.

Me pregunté por qué la artista había necesitado irse hasta Brasil a grabar paisajes y niños para contar su historia personal, aunque ella no tuviera la intención de hacerlo así. Relacioné otra vez esta obra con la obra de Chantal Akerman. Busqué en internet su biografía, la cual resultó reducida pero útil: "Akerman nació en una familia judía practicante de Bruselas. Sus abuelos y su madre fueron enviados a Auschwitz, solo se salvó su madre. La ansiedad materna y el exilio serán temas recurrentes en su filmografía." Luego volví a observar los textos descriptivos de la obra y una frase que me había parecido no tener importancia tomó sentido: "Viajando bajo una impulsión literaria relacionada con Faulkner y Baldwin, atraviesa (Akerman) Alabama, Misisipi, Luisiana, Georgia y se establece en Jasper, Texas. A su llegada, se entera de un suceso racial: El linchamiento de James Byrd." (Bonnet, 2006). Esto me llevó a asociar el interés por este crimen racial con la propia historia de la artista. Entendiendo que, indirectamente, hablar del crimen racial de James Byrd era hablar de otros crímenes raciales que marcaron su historia personal o la historia de la humanidad.

La pregunta "¿soy yo (el artista, realizador) quien elige los sujetos o los sujetos me eligen?" volvió a tomar consistencia. Jacques Sorieger (Universidad de Provence, Francia), en un examen de titulación de doctorado, dijo: "Es lo que hago lo que me lleva a saber lo que busco".

Ni Chantal Akerman ni Eliane Chiron buscaron traba- jar sobre sus historias personales, sino que estas parecen haber surgido en el transcurso de sus búsquedas, de las construcciones de sus obras. Si yo elijo un tema de trabajo, otro puede llegar a mí (como en el caso de Sud) y rebasar el que he elegido. De este modo, se encuentran mutuamente el sujeto y la persona que va a sensibilizarse con él (por su historia, su experiencia, sus intereses...).

La obra funciona, entonces, como una interface entre lo íntimo y lo público, entre el mundo interior del artista y el mundo exterior. Suzanne Müller (2000) en un texto breve, publicado en L'intime, le privé, le public, reutiliza el término de unheimlich para hablar de este paso de lo íntimo a lo público, de lo familiar a lo extraño.

El término unheimlich fue analizado a fondo por Freud en 1919 en su texto Das Unheimliche. El adjetivo alemán unheimlich, por su prefijo un-, niega a heimlich, que significa "que forma parte de la casa, no extraño, familiar, domado, querido e íntimo", y también "escondido, disimulado, de tal forma que no queremos que otros lo conozcan." Designa literalmente lo no familiar. La negación no, en una perspectiva psicoanalítica, es la marca de la censura que revela la proximidad entre la cosa y su contrario. Freud propone una primera definición: "este heimlich no es en realidad nada nuevo o extraño, pero sí un poco para la vida psíquica familiar de siempre, el cual se volvió extraño tras el proceso de represión". Entonces se trata de "esta variedad particular de lo ominoso que remonta al 'desde mucho tiempo conocido', 'desde mucho tiempo familiar'”. Suzanne Müller propone la siguiente traducción: Unheimlich = inquietante familiaridad (con la finalidad de dar cuenta del carácter paradójico del término). En los procesos creativos como en las obras, este unheimlich aparece y actúa. Es posible que en el proceso creativo el "acontecimiento reprimido" regrese a la superficie, realizando esta catarsis estudiada por Freud.

Diferentes procesos ficcionales permiten el surgimiento de esta "inquietante familiaridad" en la trama de lo real. Los manglares, la carretera, los campos de algodón, los árboles no representan esta naturaleza apacible. Grabada, utilizada, mezclada, construida, digerida por los artistas, esta naturaleza se tiñe de una interioridad, una intimidad. Sucede que lo representado, el campo de algodón, por ejemplo, en Sud, nos resulta conocido, familiar; la imagen no está alterada, se presenta a nosotros sin modificaciones en su representación. Lo que sí nos altera, después de un momento de observarlo, es el tiempo que nos da la artista para verlo; el campo, en un tiempo extenso, se transforma sutilmente sin que nos demos cuenta. Del campo conocido o reconocido que pensábamos observar, se pasa a un campo inquietante, no tan pasivo, no tan mudo. El campo empieza a hablar, a volverse un testigo pasivo que se revela como la escenografía de matanzas pasadas. Se pinta de una inquietante familiaridad. 


\section{De la distancia}

Recordé otra vez la distancia que existe entre el país de Chantal Akerman (Bélgica) y el lugar donde fue a desenterrar su propia historia; también aquella entre el país de Eliane Chiron (Francia) y el país al cual fue a buscar sus fantasmas (Brasil); me pregunté cómo la distancia podía ayudar a hablar de su propia historia, de quiénes somos, a través de un extraño movimiento que nos acerca por medio del alejamiento. Creando una separación entre sí y su mundo, el viaje nos acerca paradójicamente a lo que olvidamos, a lo que no sabemos o ya no podemos decir. En esta película, Chantal Akerman busca cómo hablar, cómo mostrar el horror (cuyo recuerdo la habita, la confronta siempre). El viaje es parte, desde hace mucho tiempo, de los procesos poéticos de los artistas que buscan, a través del desplazamiento geográfico, al otro que quizá los llevará a entenderse a ellos mismos.

También me pregunté cuál era el papel del otro en esta búsqueda. Cómo se habían acercado al otro, por medio de qué, de cuáles estereotipos, de cuáles estrategias. Me di cuenta que sus observaciones, sus miradas, imágenes, estaban más orientadas por sus lecturas, sus "museos imaginarios", que por la realidad vivida. A fin de cuentas, observé que el otro no era tan importante (sobre todo en el caso de Eliane Chiron) como el proceso de la memoria. Estos videos podrían parecer territorios de la memoria; no se trata de documentales pero sí de cartografías de la memoria, de una lenta superposición del pasado sobre el presente a través del paisaje. Chantal Akerman (2003) dijo a propósito de Sud: "también tuve ganas de ir a ver allá [...] si este paisaje guardaba las marcas o el recuerdo de otra cosa aparte de su propia belleza".

El paisaje aparece, en estas obras, como la huella de una historia por contar. Se trata de una mirada poética, contemplativa, histórica que la artista busca, investiga y captura con los paisajes para hablar de los muertos suyos y de los otros. En el artículo "El trabajo de la imagen" de Jacques Rancière (2006), el teórico plantea la pregunta que muchos se hacen: ¿Podemos y debemos representar el horror de los campos de concentración (relativo a la historia de la Segunda Guerra Mundial)? Yo replantearía la pregunta así: ¿Podemos y debemos representar el horror? Los que plantean esta pregunta tienen ya la respuesta, la cual se despliega sobre un triple nivel:

1. Representar es dar a conocer y no se tiene que ofrecer al placer de los ojos una humillación y deshumanización, salvo volviéndose cómplice.

2. Representar es construir una historia y no se debe dar la racionalidad a una historia construida en la exterminación, excepto dándola como aceptable.

3. Representar es elegir el partido de los idólatras, es prolongar el crimen contra el pueblo.
Todas estas respuestas apuntan a un mismo principio; asimilan la representación en la superchería que toma el lugar de algo en su ausencia -visión de cuerpos maltratados y humillados (como lo pudimos ver en el caso de James Byrd en los noticieros] que ya no están aquí para responder a su condición- a la ficción inapropiada de la singularidad del evento. Para ellos, representar es como mentir a la verdad del hecho.

Ahora bien, Chantal Akerman refuta estos prejuicios. Por un lado, la cosa misma lla muerte de James Byrd, o la muerte de su pueblo] nunca está aquí, solamente hay imágenes que no presentan el momento de su muerte, sino lo que dicen los paisajes, los cuerpos y sus gestos. Se trata más de presencia que de representación. La presencia de los campos de algodón, de las calles, de sus casas, de los testigos, etc. Aquí no se trata de la memoria de los muertos, pero sí de la memoria de los vivos. Esta memoria pasa por un trabajo: Hacer hablar a estos objetos, paisajes, "testigos mudos" de la vida de los hombres.

A través de estos procesos creativos, la imagen de la muerte toma forma, se vuelve sensible, humana. Como se citó: "entramos en su propio imaginario [del espectador] y tenemos una sensación, y esto no es información, es sentir. La información, la vemos todos los días y la gente la olvida al día siguiente."

(Akerman, 2003)

Para cerrar esta investigación, propongamos un ejercicio. Imaginemos que temprano, como cada día, usted sale para ir a trabajar, o a llevar a sus hijos a la escuela o a comprar pan, y en el camino se encuentra con un muerto de verdad. ¿Qué podría hacer usted? ¿Alejarse para no verlo o al contrario acercarse para ver quién es, cómo fue la muerte, o gritar, llamar a la policía, o sacarle una foto y publicarla en Facebook...? Si fuera yo, me alejaría; quizá porque en mi cultura le tenemos un cierto miedo a los muertos, a la muerte. No lo podría mirar. Por eso quizá desde hace muchos años he tomado la decisión de no tener televisión en mi casa, porque la televisión llena mi casa de objetos, de imágenes que no deseo ver. ¿Qué sucede cuando uno deja que entre en su casa toda esta violencia visual?

Si la relación con la muerte se vulgarizó a partir de los medios de comunicación y de su tratamiento visual, creo que es una tarea importante la que llevan a cabo algunos cineastas o videastas al plantearse el tema de la representación de la violencia y de la muerte en la pantalla desde otra puesta en escena. Es esta puesta en escena la que va a cuestionar las relaciones del espectador con un sistema de representación mediática que no solo no la plantea (la puesta en escena), sino que también tiene miedo de plantearla o hace todo para evitarla. 
Estas artistas ponen en duda, por medio de sus puestas en escena y sus imágenes, lo que los medios nos habían acostumbrado a percibir: Una relación fría y deshumanizada con la muerte. Las imágenes de Chantal Akerman nacen tras un proceso de ponerse en relación ella misma (como artista) con el entorno de James Byrd. Y es al ponerse en contacto con los futuros personajes y paisajes (es decir, en los detalles del acercamiento] que se establece lo esencial de la película.

Frente a la indiferencia de las representaciones mediáticas, las obras estudiadas vuelven a insuflar lo humano, la poesía, lo sensible y lo mágico en nuestra relación con la vida y con la muerte. Y lo insuflan porque las artistas se implican en este proceso.

¿Pero técnicamente podría la televisión, "si quisiera" (porque no es el caso), ofrecer un destino diferente a los muertos y a la violencia? Modificando los lugares y las posiciones de poder, sí. Quizá sería muy difícil y exhausto imaginarse que cada camarógrafo tuviera que acercarse íntimamente con el muerto y su entorno para poder hablar de él. Tal vez se trataría de soltar el poder; el que tiene el poder de hacer las imágenes cederlo al que por acostumbre las mira, las recibe. Quizá tendría que ser la familia o alguien cercano al muerto quien debería de tomar la cámara y elegir qué mostrar o qué no, desde qué punto de vista, a partir de qué historia; de este modo, la representación perdería su indiferencia, para dar una forma singular a la capacidad de hacer y de decir que nos pertenece a todos.

\section{Referencias}

Akerman, Chantal (2003). "Interview con Laurent Devanne" en CinEast, Disponible en http://www.arkepix.com/kinok/Chantal\%2OAKERMAN/akerman_interview.html, consultado el 6 de febrero de 2014.

(2012). "Chantal Akerman, Cinéma cinéaste" en Webzine, No. 170. Disponible en http://www.cinergie.be/ webzine/chantal_akerman_cinema_cineaste, consultado el 6 de febrero 2014.

Barthes, Roland (1957). Mythologies. Paris: Ed. Seuil.

Bonnet, Sophie (2006). Sud, Les Inrocks. Disponible en http:// www. lesinrocks.com/cinema/films-a-l-affiche/sud/, consultado el 6 de febrero del 2014.

Chiron, Eliane (2013). Peau et vidéo numérique. Interfaces avec la mangrove brésilienne (Piel y video digital. Interfaces con el manglar brasileño], en el coloquio "Les technologies dans la peau. De la singularité a la peau du monde". LARA (Laboratorio de investigación en audiovisual), Université Toulouse le Mirail II.

Comolli, Jean Louis (2004). Voir et pouvoir (Ver y poder). Paris: Ed. Verdier.

Cropper, Carol Marie (1998). Black Man Fatally Dragged in a Possible Racial Killing, archivos del New York Times. Disponible en http://www. nytimes.com/1998/06/10/us/black-man-fatallydragged-in-a-possible-racial-killing.html, consultado el 27 de enero de 2014.

Freud, Sigmund (1919). Linquiétante étrangeté et autres essais, traducido del alemán por B. Feron, Paris: Ed. Gallimard.

Mullër, Suzanne (2000). "L'Unheimlich a l'oeuvre. Passages de l'intime au public et du familier à l'étrange dans l'art contemporain" (Pasajes de lo íntimo a lo público y de lo familiar a lo extraño en el arte contemporáneo], en L'intime, le privé, le public dans l'art contemporain. Paris: Ed. La Sorbonne.

Rancière, Jacques (2006). Le travail de l'image (El trabajo de la imagen]. Disponible en http://www.egs.edu/faculty/jacquesranciere/articles/le-travail-de-limage/, consultado el 26 de marzo 2014.

Ruiz, Raúl (1995). Poética del cine. Paris: Dis-voir. 
tat

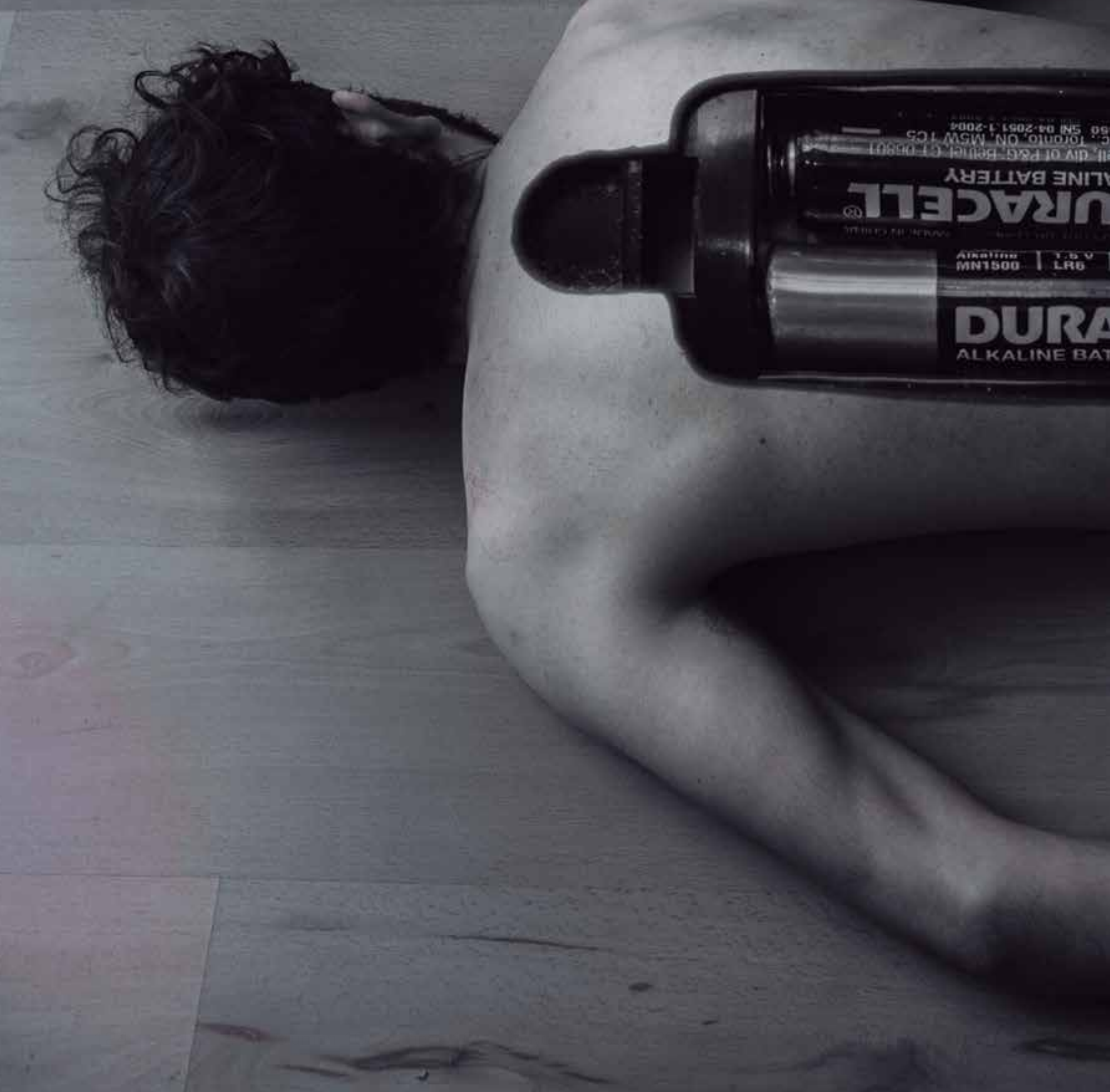




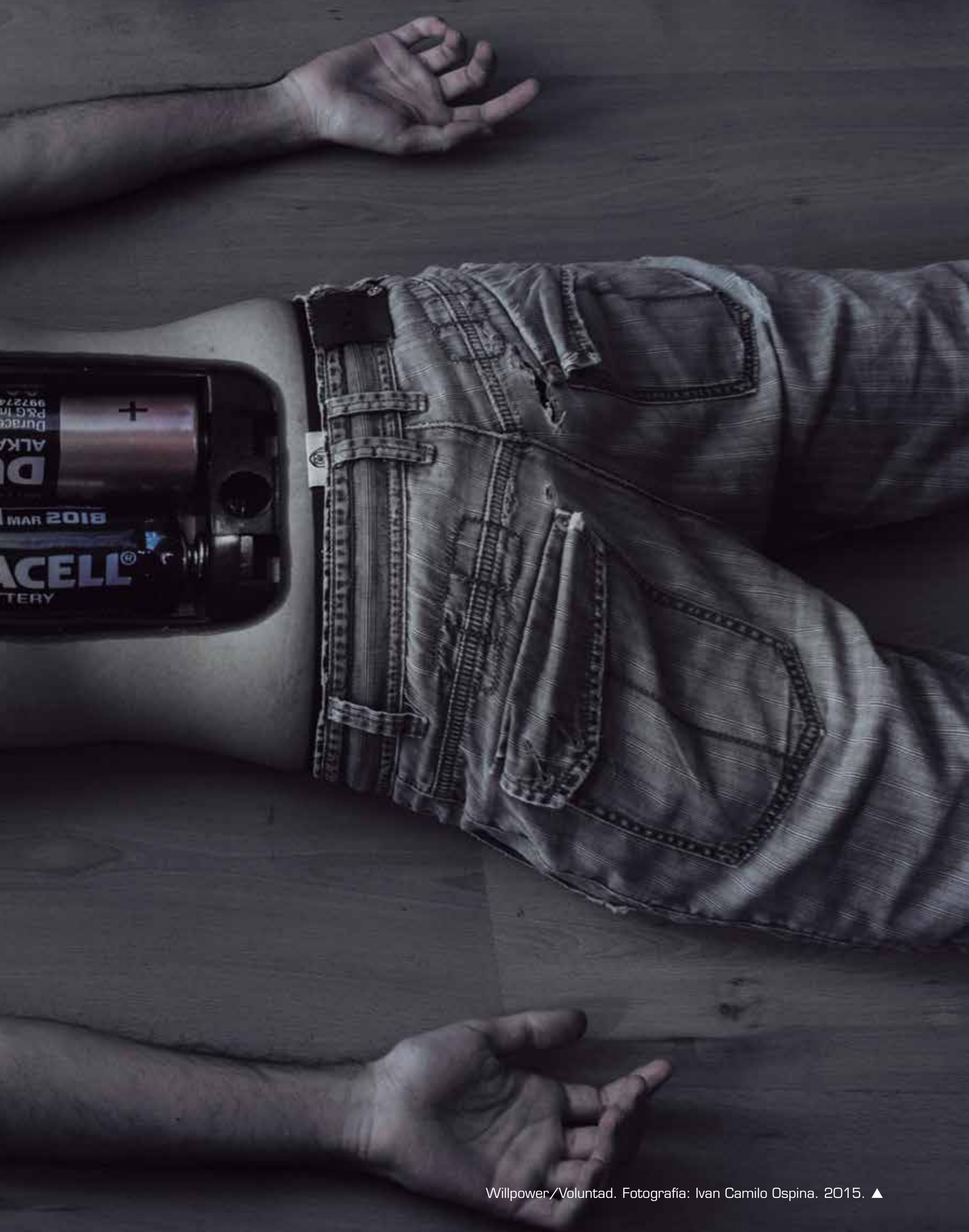

